\title{
EDUCAÇÃO AMBIENTAL AO AR LIVRE: INTERVENÇÕES EM ESPORTES NA NATUREZA
}

\author{
Rodrigo Cavasini ${ }^{1}$ \\ Ricardo Demétrio de Souza Petersen ${ }^{2}$ \\ Lucio de Albuquerque Jacometti ${ }^{3}$ \\ Rafael Falcão Breyer ${ }^{4}$
}

Resumo: Este trabalho relata as experiências de intervenções de educação ambiental ao ar livre realizadas pelo Projeto PST/Navegar da Escola de Educação Física (ESEF) da Universidade Federal do Rio Grande do Sul (UFRGS). Tais propostas educacionais focam em práticas de mínimo impacto ambiental em esportes na natureza, baseadas em Princípios de Não Deixar Rastros (Leave no Trace Principles), e em intervenções de educação ambiental realizadas no contexto de atividades na natureza, que se centram em intervenções educacionais sobre, no e para o meio ambiente. Durante os dez anos de existência desse Projeto, as experiências de educação ambiental ao ar livre têm sido constantemente avaliadas e aprimoradas.

Palavras-chave: Educação Ambiental; Esportes na Natureza; Inclusão Social.

\footnotetext{
${ }^{1}$ Pontifícia Universidade Católica do Rio Grande do Sul. E-mail: rcavasini@yahoo.com.br

${ }^{2}$ Universidade Federal do Rio Grande do Sul. E-mail: petersen@esef.ufrgs.br

${ }^{3}$ E-mail: lucio.esef@gmail.com

${ }^{4}$ E-mail: rfbreyer@gmail.com
} 


\section{Introdução}

Durante as últimas décadas, a degradação e os impactos ambientais que vêm sendo gerados, acelerados e ampliados pela ação inconsequente da humanidade têm atingido escalas preocupantes. Dessa forma, problemáticas relacionadas aos resíduos produzidos, ao aquecimento global, à poluição e contaminação de recursos hídricos, entre outras, conquistaram um espaço crescente na mídia, em discussões, em pesquisas e em eventos realizados por diferentes setores da sociedade.

Frente a esse quadro, inúmeros esforços têm sido realizados para o enfrentamento dessas questões, entretanto, a complexidade da situação atual demanda ações efetivas, as quais produzam um maior impacto na realidade mundial. As intervenções de educação ambiental despontam como alternativas relevantes, uma vez que, podem ser utilizadas como importantes ferramentas para o enfrentamento dessas problemáticas que afetam o meio ambiente e a sociedade como um todo.

No Brasil, um número expressivo de intervenções de educação ambiental vem sendo promovidas, pesquisadas e avaliadas, tanto em ambientes educacionais formais, quanto informais. Entretanto, a educação ambiental que é um tema transversal e pode ser caracterizada pela pluralidade de manifestações, ainda é pouco presente em atividades esportivas realizadas na natureza. Mesmo com a existência de consideráveis potencialidades ${ }^{5}$ e a expansão dos números de praticantes e interessados nesses esportes na natureza, permanece pouco expressivo o número de intervenções estruturadas de educação ambiental desenvolvidas em conjunto desses esportes. Assim, explicitando a relevância da ampliação do conhecimento sobre essa temática para que seja possível estimular e instrumentar a realização de outros estudos, bem como de intervenções de atividades de educação ambiental desenvolvidas nesse contexto.

Esse relato de experiência centra-se nas experiências de intervenções de educação ambiental ao ar livre realizadas pelo Projeto PST/Navegar da Universidade Federal do Rio Grande do Sul ou, simplesmente, Projeto PST/Navegar UFRGS. Para tanto, o texto que segue está organizado em três partes: primeiramente serão abordadas características gerais desse projeto, como objetivos, locais empregados para a realização das atividades propostas, aspectos relacionados à equipe de trabalho e aos alunos participantes; a segunda parte centra-se na educação ambiental ao ar livre, em que são abordados aspectos das práticas de mínimo impacto ambiental em esportes na natureza e de intervenções de educação ambiental realizadas no contexto

\footnotetext{
${ }^{5}$ Os esportes praticados na natureza possuem potencialidades relacionadas a aspectos pessoais, sociais, ambientais e econômicos (MANNING, 2011; CAVASINI, 2008).
} 
desses esportes, além da metodologia de tabalho desenvolvida no Projeto PST/Navegar UFRGS; por fim, são apresentadas algumas considerações e perspectivas futuras.

\section{Características Gerais do Projeto PST/Navegar UFRGS}

O PST/Navegar UFRGS é desenvolvido pela Escola de Educação Física (ESEF) desde 2003 e busca democratizar o acesso a atividades esportivas e educacionais realizadas em contato com a natureza, como instrumento de promoção de inclusão social para adolescentes. Para tanto, conta com recursos provenientes do Ministério do Esporte, além de suporte da UFRGS e parcerias com instituições públicas e privadas. Dessa forma, torna-se possível o desenvolvimento, sem custos para os participantes, de atividades de iniciação de vela, remo e canoagem, intervenções de educação ambiental ao ar livre e outras propostas complementares, como 0 xadrez e atividades recreativas. Entre seus objetivos, destacam-se: oferecer práticas esportivas educacionais de qualidade; auxiliar no desenvolvimento de capacidades físicas e habilidades motoras; contribuir para a melhoria da qualidade de vida; diminuir a exposição aos riscos sociais; promover o desenvolvimento de competências relevantes para o aprimoramento e manutenção da qualidade do meio ambiente; colaborar na formação da equipe de trabalho; estimular a integração com as comunidades envolvidas.

As áreas empregadas para a realização do PST/Navegar UFRGS situam-se na região próxima à Doca Turística, na Zona Norte de Porto Alegre (Figura 1). Esses locais possuem histórico considerável, no que se refere a atividades esportivas realizadas em contato com a natureza, principalmente no Lago Guaíba, sendo também a localização de vários clubes de remo do estado do Rio Grande do Sul e a origem de clubes de vela, como o Veleiros do Sul. Nesse sentido, as áreas do Lago Guaíba empregadas para o desenvolvimento das atividades propostas pelo Projeto apresentam características que tornam possível a realização simultânea das três modalidades, que possuem demandas diferenciadas. Além disso, esses espaços situam-se próximos ao Parque Estadual do Delta do Jacuí que é uma unidade de conservação marcada pela existência de áreas de grande beleza natural, como as regiões próximas a Ilha das Garças, e outras fortemente impactadas pela ação do homem, como a foz do Rio Gravataí. Enfim, áreas cujas características apresentam consideráveis potencialidades para 0 desenvolvimento das propostas esportivas e educacionais do Projeto PST/Navegar UFRGS. 


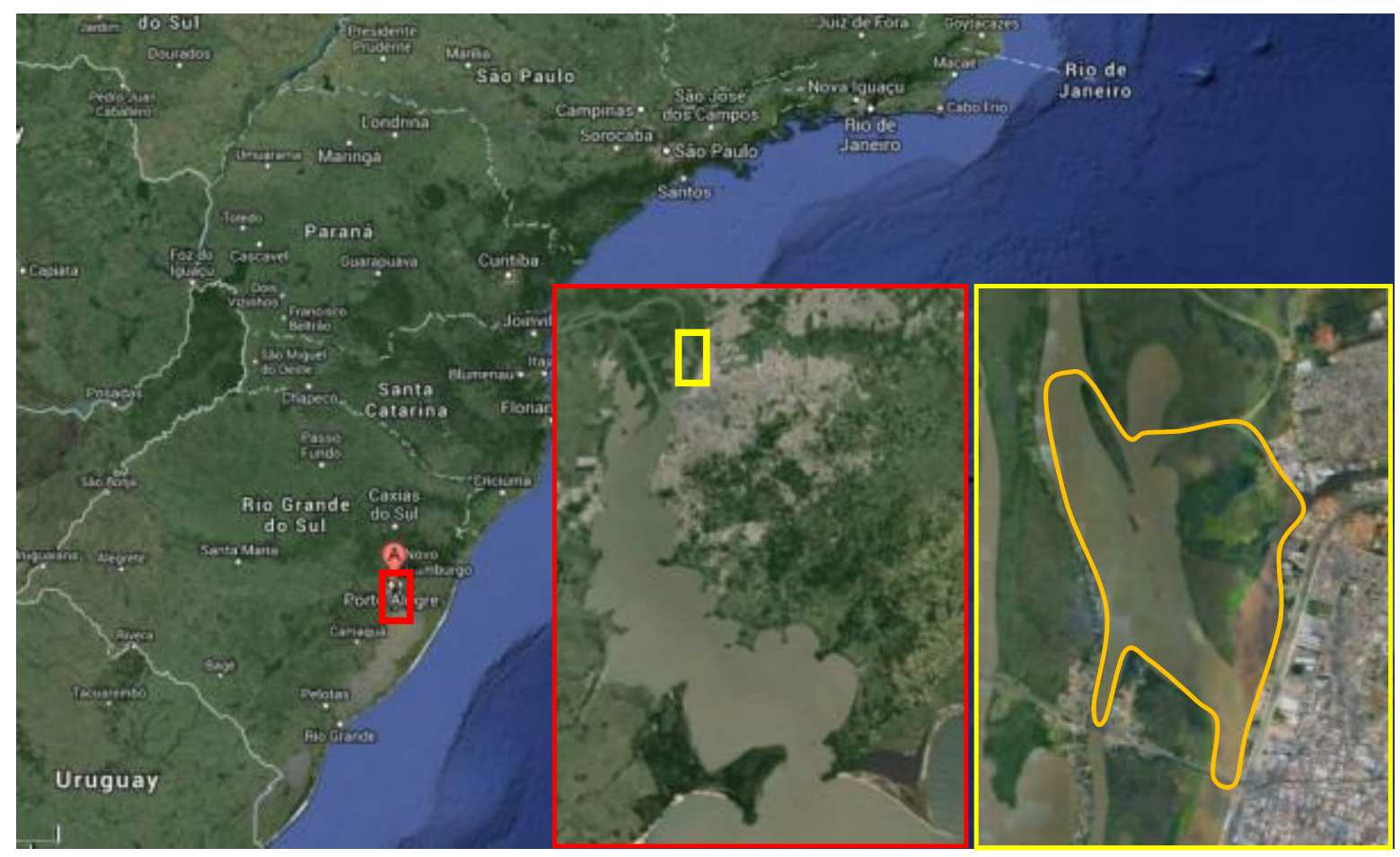

Figura 1: Áreas empregadas pelo Projeto PST/Navegar UFRGS. Fonte: Google Earth.

A equipe de trabalho do Projeto PST/Navegar UFRGS é formada por professores e estudantes de Educação Física. Os primeiros atuam nas atribuições de coordenador geral, coordenador técnico-pedagógico e professores de modalidades esportivas educacionais, ao passo que, os estudantes atuam em monitorias de atividades esportivas educacionais. A equipe de professores é formada por profissionais pós-graduados em diferentes áreas, os quais possuem expertise em projetos esportivos sociais, em especial, com atividades esportivas e educacionais realizadas em contato com a natureza. Por sua vez, os estudantes, são alunos dos cursos de bacharelado e licenciatura em Educação Física que encontram no PST/Navegar UFRGS condições, tanto para atuação na área de projetos esportivos sociais, esportes na natureza e educação ambiental ao ar livre, como para a complementação de suas formações acadêmicas e profissionais. Salienta-se que desde 0 início das atividades do Projeto, mais de 30 professores e um número superior a 120 estudantes de graduação em Educação Física e de outros cursos tiveram a oportunidade de participar, direta ou indiretamente, das atividades desenvolvidas.

A proposta de formação da equipe de trabalho figura entre os objetivos do PST/Navegar UFRGS e, tanto atende ao modelo proposto pelo Ministério do Esporte, quanto inclui outros temas, gerados pelas demandas locais. Nesse 
sentido, são promovidas atividades específicas de capacitação periodicamente, com carga horária superior a 40 horas e que empregam abordagens teóricas e práticas, bem como encontros semanais, que objetivam complementar tal formação. Em relação aos temas desenvolvidos e autores utilizados, destacamse os seguintes: características de iniciativas esportivas sociais e de práticas esportivas educacionais (OLIVEIRA; PERIN, 2009; 2008); práticas de mínimo impacto ambiental em atividades na natureza (LNT, 2013; MCGIVNEY, 2003; TILTON, 2003); educação ambiental ao ar livre (PARRY, 2013; SOBEL, 2011; 2005; CORNELL, 2008; 1998; GOOKIN; WELLS, 2002); aspectos técnicos e didáticos das modalidades de remo, vela e canoagem (CAVASINI; PETERSEN; PETKOWICZ, no prelo); gestão de riscos em atividades na natureza (DICKSON; GRAY, 2012).

No que se refere ao público alvo, esse é composto por 200 adolescentes, com idades entre 11 e 16 anos, todos matriculados na rede pública de ensino que, em sua maioria, possuem reduzidas ou nenhuma experiência anterior com as atividades esportivas e educacionais promovidas no Projeto. Desde 2003, foram atendidos mais de 2000 estudantes que residiam em locais como as Ilhas das Flores, Pavão, Grande dos Marinheiros e Pintada, bem como nos bairros Navegantes, Farrapos, Humaitá e Passo das Pedras. Salienta-se que algumas destas regiões apresentam elevados índices de exclusão social, figurando entre as zonas do município com os mais preocupantes índices de vulnerabilidade infanto-juvenil ${ }^{6}$ (PREFEITURA DE PORTO ALEGRE, 2007).

Os alunos participam das atividades no Projeto PST/Navegar UFRGS no contraturno escolar, duas vezes por semana, três horas por dia, contando com transporte das escolas até a sede do Projeto. Salienta-se que a equipe de trabalho é presente em todas as atividades esportivas e educacionais propostas, nas quais professores e monitores atuam em conjunto, dessa forma, permitindo que os objetivos sejam atingidos e tornando possível a efetiva aplicação da proposta de gestão de riscos, cujo aspecto mais relevante é a segurança de todos os participantes.

No que se refere às contribuições promovidas pelo Projeto aos alunos participantes, as avaliações realizadas pela equipe de trabalho apontam para diversos aspectos, entre os quais destacam-se: valorização de iniciativas focadas na democratização ao acesso de atividades esportivas e educacionais realizadas na natureza; ampliação do interesse por questões ambientalmente relevantes; ampliação de percepção da relevância do Lago Guaíba, do Parque Estadual do Delta do Jacuí e de aspectos relacionados à esses. Salienta-se

\footnotetext{
${ }^{6} \mathrm{O}$ índice de vulnerabilidade infanto-juvenil é uma relação entre o percentual de crianças e adolescentes com a taxa de homicídios de uma determinada região (PREFEITURA DE PORTO ALEGRE, 2007).
} 
que essas contribuições, recorrentes nos relatos dos adolescentes, vão ao encontro das falas de professores e responsáveis, no que se refere a fatos ocorridos tanto no ambiente escolar, como no ambiente familiar.

Além das informações levantadas pelas avaliações realizadas pela equipe de trabalho, o trabalho de Cavasini (2008) também aponta para as seguintes contribuições: desenvolvimento de conhecimentos relacionados aos benefícios à saúde gerados pela prática de esportes e a manutenção de um estilo de vida ativo; relatos de melhorias no comportamento e desempenho escolar; identificação do potencial dos esportes para desestimular o uso de drogas e o envolvimento em atos de delinquência; desenvolvimento de competências relevantes para a manutenção e aprimoramento da qualidade do meio ambiente; desenvolvimento de competências para o trabalho em equipe e de liderança.

\section{Educação Ambiental ao Ar Livre: A Metodologia de Trabalho do Projeto PST/Navegar UFRGS}

As intervenções de educação ambiental encontram nos esportes, como a vela, o remo e a canoagem, um ambiente propício para sua realização, devido à proximidade com a natureza, interesse dos praticantes e consideráveis potencialidades educacionais dessas atividades (CAVASINI, 2012). Nesse sentido, a educação ambiental ao ar livre pode ser organizada em torno de práticas de mínimo impacto ambiental e de atividades de educação ambiental realizadas no contexto dos esportes na natureza.

Em relação às práticas de mínimo impacto ambiental em esportes na natureza, as propostas educacionais desenvolvidas pelo Centro de Ética em Atividades ao Ar Livre - Não Deixe Rastro figuram entre as mais utilizadas. De fato, dezenas de milhares de indivíduos participam anualmente de atividades educacionais, que objetivam evitar ou minimizar os impactos em áreas naturais, também assegurando experiências positivas aos praticantes desses esportes. Essas propostas educacionais são organizadas em níveis que abrangem simples intervenções e cursos de caráter prático e/ou teórico, os quais podem ser exemplificados pelos Princípios de Não Deixar Rastro - Áreas de Grande Visitação (Leave no Trace Principles - Frountcountry Aproach).

Os Princípios de Não Deixar Rastro, de acordo com The Leave no Trace Center for Outdoor Ethics (2013), Tilton (2003) e McGivney (2003), podem ser organizados da seguinte forma: conhecer antes de ir, ou seja, a valorização do planejamento de qualquer atividade que for promovida junto à natureza; permanecer nas trilhas e acampar em locais permitidos, que foca na importância da utilização de locais adequados e/ou previamente determinados para a realização de atividades na natureza; dar um fim apropriado aos resíduos produzidos, ou seja, a relevância de organizar as atividades de 
modo a empregar, sempre que possível, os sanitários existentes nos locais escolhidos para as atividades, além de trazer de volta e encaminhar adequadamente tudo que for levado para a natureza; deixar os locais como foram encontrados, que busca salientar a relevância de não alterar os locais empregados para as atividades, assim, prevenindo danos permanentes a árvores, arbustos, locais e objetos de valor histórico e/ou cultural, além de permitir a satisfação e o senso de descoberta de outros indivíduos, quando da visitação dos mesmos locais em momentos seguintes; permitir que os animais silvestres mantenham-se silvestres, ou seja, a relevância de promover as atividades esportivas, educacionais e recreativas de modo que, os participantes não alimentem e mantenham-se distantes de animais silvestres; compartilhar as trilhas e cuidar dos animais de estimação, que salienta a relevância de considerar e respeitar outros indivíduos, os quais possam estar no mesmos locais e horários empregados para a realização dos esportes propostos, além de, manter animais de estimação sob controle e recolher seus dejetos, caso estejam presentes em atividades na natureza.

Por sua vez, as intervenções de educação ambiental realizadas no contexto dos esportes na natureza relacionam-se diretamente com abordagens educacionais organizadas em três grupos: educação sobre o meio ambiente, que propicia informações sobre os fenômenos ambientais; educação no meio ambiente que emprega atividades ao ar livre, como os esportes na natureza para o desenvolvimento de habilidades e aprendizados; e a educação para o meio ambiente, em que as intervenções são direcionadas para o enfrentamento de problemáticas ambientais (CAVASINI, 2012; MINISTRY FOR THE ENVIRONMENT OF NEW ZEALAND, 1998).

De acordo com Castro (1999), a educação sobre o meio ambiente centra-se em abordagens teóricas para o descobrimento da natureza, objetivando o desenvolvimento de conhecimentos sobre interações do ser humano com o meio ambiente. Por sua vez, a educação no meio ambiente utiliza os espaços naturais como uma fonte de materiais para a realização de atividades educacionais experienciais. Esse enfoque, corriqueiro nas iniciativas não formais de educação ambiental, costuma empregar diferentes atividades físicas, como as próprias atividades esportivas.

Já a educação para o meio ambiente objetiva promover a participação ativa do indivíduo e de grupos sociais na busca por resoluções de problemáticas ambientais. Nesse sentido, Giordan e Souchon (1995) apud Castro (1999) salientam que tal abordagem baseia-se na compreensão de que as problemáticas ambientais relacionam-se direta ou indiretamente com a utilização e gestão que a humanidade realiza de recursos naturais, enfatizando a importância da utilização adequada e manutenção da qualidade do meio ambiente.

Salienta-se que o emprego de atividades educacionais no e para o meio ambiente, que podem ser desenvolvidas durante a prática de esportes na 
natureza, combinadas com atividades educacionais sobre o meio ambiente, facilmente realizadas no início e final de cada aula, demonstra ser uma abordagem de elevado potencial educacional (MAZZE, 2006). De fato, essa forma de promoção da educação ambiental permite o desenvolvimento de um número expressivo de fatores relacionados ao desenvolvimento de comportamentos ambientalmente responsáveis (DUERDEN; WITT, 2010), além de ser uma proposta educacional de grande interesse da população (CAVASINI, 2012).

A metodologia de trabalho proposta para as atividades de educação ambiental ao ar livre realizadas pelo Projeto PST/Navegar UFRGS é desenvolvida em intervenções que ocorrem no dia-a-dia e em encontros específicos. Nesse sentido, alguns dos conteúdos que integram tal proposta se relacionam com problemáticas relacionadas aos resíduos sólidos; perspectivas sobre o RRR - reduzir, reutilizar e reciclar; poluição e contaminação dos recursos hídricos; impactos ambientais causados pelo homem; práticas de mínimo impacto ambiental em esportes na natureza.

Em relação às intervenções que ocorrem no cotidiano do Projeto, os momentos iniciais de cada aula são empregados para abordar conteúdos relacionados a questões ambientalmente relevantes, paralelamente à apresentação de objetivos e atividades planejadas (educação sobre o meio ambiente). Na água ou em terra, durante o desenvolvimento de conteúdos das atividades esportivas, os alunos também são estimulados para que percebam os espaços em que eles estão inseridos, relacionando-os com as questões anteriormente abordadas (educação no meio ambiente). Já no encerramento das atividades, são novamente tratados os assuntos abordados inicialmente e as experiências realizadas, assim, buscando a construção de respostas e novos questionamentos (educação para o meio ambiente).

No que se refere aos encontros específicos, o quadro abaixo ilustra um dos ciclos pedagógicos empregados pelo Projeto, com 28 encontros, em que estão destacadas as aulas de educação ambiental ao ar livre (Quadro 1). Salienta-se que as duas primeiras intervenções são promovidas por cada turma individualmente, ao passo que as seguintes ocorrem em conjunto pelas três turmas. 
Quadro 1: llustração de um ciclo pedagógico do Projeto PST/Navegar UFRGS.

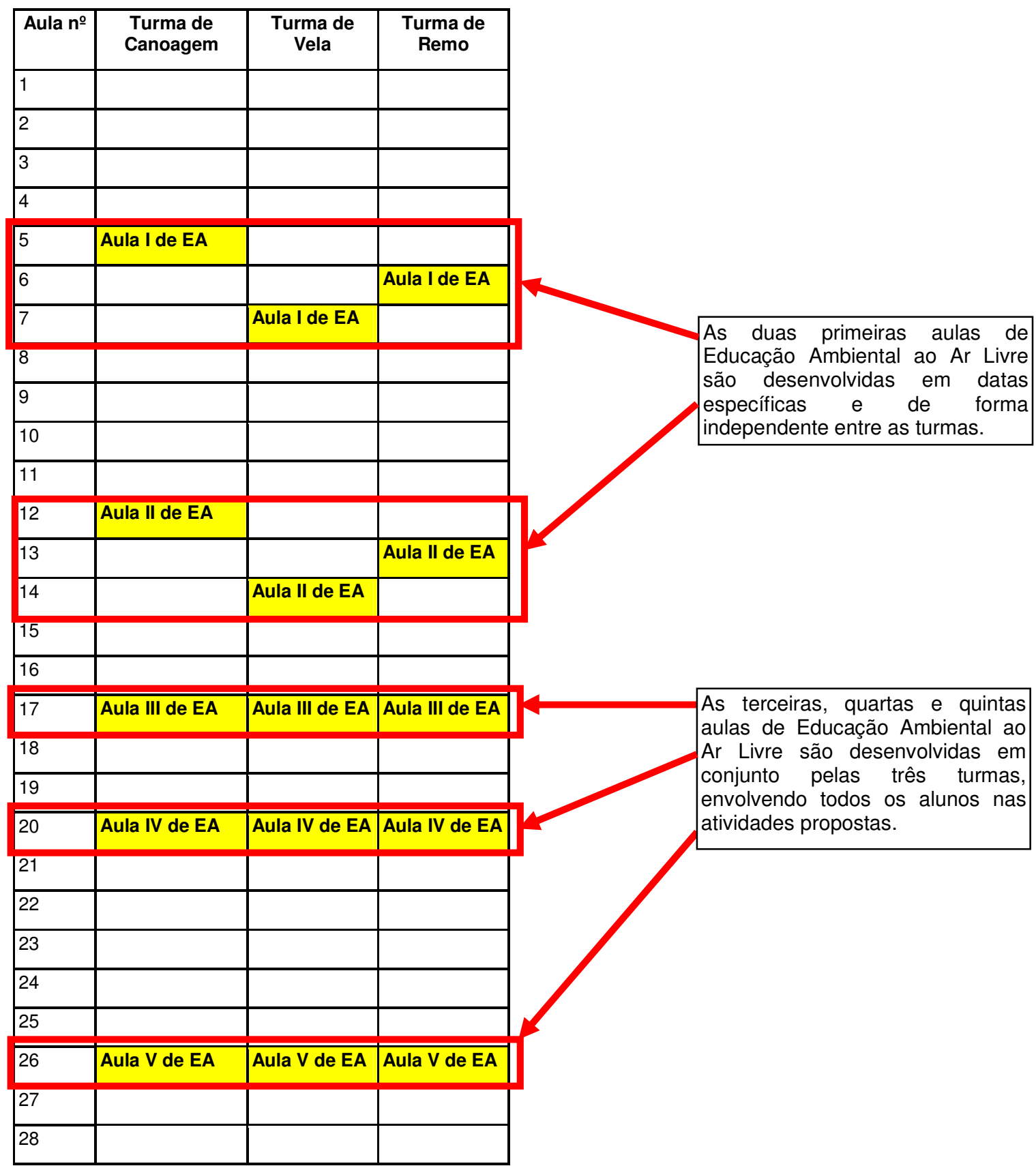

Os planos de aula das intervenções de educação ambiental promovidas pelo Projeto PST/Navegar UFRGS centram-se tanto na promoção de práticas de mínimo impacto ambiental em esportes na natureza, quanto em intervenções de educação promovidas no contexto desses esportes (Quadro 2). Nesse sentido, o quadro a seguir permite uma melhor compreensão da proposta. 
Quadro 2: Os planos de aula das intervenções de educação ambiental promovidas pelo Projeto PST/Navegar UFRGS

\begin{tabular}{|l|}
\hline Aula I \\
\hline $\begin{array}{l}\text { Discussões iniciais (40 minutos) relacionadas a conteúdos como poluição de recursos hídricos e da } \\
\text { atmosfera, impactos ambientais causados pelo homem e problemáticas relacionadas aos resíduos. }\end{array}$ \\
\hline $\begin{array}{l}\text { Remada/velejada até a foz do rio Gravataí (100 minutos) para experienciar aspectos dos conteúdos } \\
\text { tratados anteriormente. }\end{array}$ \\
\hline Discussões finais (20 minutos) sobre as experiências construídas na aula. \\
\hline
\end{tabular}

\section{Aula II e III}

Discussões iniciais (30 minutos) relacionadas a conteúdos como impactos ambientais causados pelo homem, problemáticas relacionadas aos resíduos, perspectivas sobre o RRR e práticas de mínimo impacto nos esportes de natureza.

Remada/Velejada e recolhimento de materiais em margens das Ilhas do Pavão e do Humaitá (90 minutos) em que os alunos, em suas embarcações, promovem ações para o recolhimento de materiais (ex.: garrafas PET e isopor).

Organização dos materiais coletados (20 minutos) para reciclagem ou posterior reutilização, como flutuantes auxiliares nos caiaques e barcos de vela.

Discussões finais (20 minutos) sobre as experiências construídas na aula.

Aula IV

Discussões iniciais (20 minutos) relacionadas a conteúdos como perspectivas sobre o RRR e práticas de mínimo impacto nos esportes de natureza.

Construção de equipamentos (110 minutos) que ampliem a flutuação das embarcações, empregando materiais que foram coletados da natureza em aulas anteriores.

Teste de flutuação (30 minutos) das embarcações que receberam as melhorias.

Discussões finais (20 minutos) sobre as experiências construídas na aula.

\begin{tabular}{|l|}
\hline Aula V \\
\hline Discussões iniciais (15 minutos) sobre diferentes abordagens de educação ambiental ao ar livre. \\
\hline Remada/Velejada (45 minutos) até praias de ilhas próximas à sede do Projeto. \\
\hline $\begin{array}{l}\text { Circuitos de desafio com cordas e atividades com vendas (60 minutos) de modo a explorar diferentes } \\
\text { aspectos dos locais e atividades propostas. }\end{array}$ \\
\hline Remada/Velejada (45 minutos) para retornar à sede do Projeto. \\
\hline Discussões finais (15 minutos) sobre as experiências construídas na aula. \\
\hline
\end{tabular}

As intervenções de educação ambiental ao ar livre promovidas pelo PST/Navegar UFRGS são constantemente avaliadas pela equipe de trabalho e de maneira pontual por professores convidados. O foco das avaliações realizadas por professores e monitores volta-se para o desenvolvimento de competências e percepções por parte dos alunos e da própria equipe. Para tanto, são empregados questionários e realizadas observações e discussões 
sobre o trabalho em andamento. Por outro lado, as avaliações executadas por professores externos ao Projeto se relacionam com a elaboração de relatórios para as instituições envolvidas e a produção de estudos, sendo os questionários e as entrevistas os instrumentos de coleta de dados mais usuais.

Em ambas as situações, os resultados obtidos apontam para 0 desenvolvimento de conhecimentos e atitudes ambientalmente relevantes. Além disso, as avaliações sugerem a ampliação das percepções dos alunos e, principalmente, de professores e monitores sobre a relevância dessas intervenções educacionais. De fato, tais resultados vão ao encontro, tanto dos relatos de professores das escolas participantes sobre os alunos participantes, como de ex-integrantes do Projeto, em relação ao planejamento e promoção de atividades de educação ambiental ao ar livre em outras iniciativas esportivas e educacionais.

\section{Outras Considerações e perspectivas}

Os esportes praticados em contato com a natureza, como a vela, o remo e a canoagem podem promover a manutenção e aprimoramento da qualidade do meio ambiente. Nesse sentido, a educação ambiental ao ar livre destaca-se, devido ao seu potencial para a minimização de impactos que possam ser produzidos, bem como para o desenvolvimento de competências para o enfrentamento de problemáticas ambientais. De fato, essas atividades educacionais se diferenciam de outras intervenções tradicionais de educação ambiental, por permitir o envolvimento ativo dos alunos, contrastando com a realidade passiva, muitas vezes encontrada em intervenções promovidas unicamente por meio de palestras, apresentações, análise de filmes e leitura de materiais.

Durante os dez anos de realização do Projeto PST/Navegar UFRGS tem-se obtido um considerável êxito, no que se refere à proposta de intervenções de educação ambiental ao ar livre. Nesse sentido, avaliações realizadas sugerem o desenvolvimento de conhecimentos e atitudes, bem como a ampliação da percepção da importância dessas atividades educacionais por parte dos alunos, professores e monitores envolvidos. Além disso, salienta-se que essa proposta é empregada pelo próprio Ministério do Esporte, em atividades de capacitação das equipes de trabalho de outros núcleos do Projeto PST/Navegar que são promovidos em diferentes localidades do Brasil.

Entretanto, alguns aspectos têm gerado desafios, sendo os elevados custos de execução do Projeto e a carência de recursos humanos qualificados para atuar na área de atividades esportivas e educacionais na natureza os mais expressivos. No que se refere aos custos e ao aporte de recursos financeiros, tratativas constantes são realizados junto ao Ministério do Esporte, instituições parceiras e com a própria Universidade, de modo a superar possíveis dificuldades. Já, frente às questões relacionadas à disponibilidade de 
recursos humanos qualificados, têm se buscado, além da capacitação interna da equipe de trabalho, estimular a formação de estudantes de Educação Física, por meio de cursos, palestras e disciplinas, inclusive na própria Escola de Educação Física da UFRGS.

Por fim, as perspectivas futuras apontam para a necessidade da continuidade dos esforços em prol do aprimoramento das atividades realizadas pelo Projeto PST/Navegar UFRGS. Nesse sentido, discussões são promovidas constantemente entre os recursos humanos envolvidos e representantes da ESEF, UFRGS, Ministério do Esporte e demais instituições parcerias, de modo a buscar alternativas para aperfeiçoamento da atual proposta e o atendimento de demandas futuras.

\section{Referências}

CASTRO, R. Educación Ambiental nos Espacios Naturais Protexidos, in: Educación Ambiental nos Espacios Naturais Galegos. Departamento de Pedagoxía e Didáctica das Ciencias Experimentais, Facultade de Ciencias da Educación, Universidade da Curuña, Espanha, 1999.

CAVASINI, R. Educação Ambiental e Atividades Físicas na Natureza. Monografia de Especialização apresentada no Curso de Especialização em Educação Ambiental da Universidade Cidade de São Paulo. São Paulo-SP, Brasil, 2012.

CAVASINI, R. Projetos Esportivos Sociais Voltados para Jovens: Um Estudo das Contribuições do Projeto Navegar de Porto Alegre. Dissertação, Programa de Pós-Graduação em Ciências do Movimento Humano da Escola de Educação Física da Universidade Federal do Rio Grande do Sul, 2008.

CAVASINI, R.; PETERSEN, R.D.S.; PETKOWICZ, F.O. PST/Navegar: Aspectos Técnicos e Pedagógicos. Universidade Federal do Rio Grande do Sul, no prelo.

CORNELL, J. Vivências com a Natureza: Guia de Atividades para Pais e Educadores. São Paulo: Aquariana, 1998.

CORNELL, J. Vivências com a Natureza, Volume 2: Novas Atividades para Pais e Educadores. São Paulo: Aquariana, 2008.

DICKSON, T.; GRAY, T. Risk Management in the Outdoors: A Whole of Organization Approach for Education, Sport and Recreation. Melbourne, Austrália: Cambridge University Press, 2012.

DUERDEN, M.D.; WITT, P.A. The Impact of Direct and Indirect Experiences on the Development of Environmental Knowledge, Attitudes and Behavior. Journal of Environmental Psychology, vol. 30, n.4, 2010.

GOOKIN, J.; WELLS, D. NOLS Environmental Education Notebook. Estados Unidos: National Outdoor Leadership School, 2002. 
KOLLMUSS, A.; AGYEMAN, J. Mind the Gap: Why Do People Act Environmentally and what Are the Barriers to Pro-Environmental Behavior? Environmental Education Research, vol. 8, n. 3, 2002.

MANNING, R. E. Studies in Outdoor Recreation: Search and Research for Satisfaction. Corvallis, EUA: Oregon State University Press, 2011.

MAZZE, S. Beyond Wilderness: Outdoor Education and the Transfer of Environmental Ethics. Dissertação apresentada no Programa de Estudos Ambientais da Universidade de Oregon, 2006.

MCGIVNEY, A. Leave No Trace A Guide To The New Wilderness Etiquette. Seattle: Mountaineers Books, 2003.

MINISTRY FOR THE ENVIRONMENT OF NEW ZEALAND . Learning to Care for our Environment: Me ako ki te tiaki taiao. Wellington, Nova Zelândia: 1998.

OLIVEIRA, A.A.B.; PERIM, G.L. (Org.) Fundamentos Pedagógicos do Programa Segundo Tempo: da Reflexão à Prática. Maringá: EDUEM, 2009.

OLIVEIRA, A.A.B.; PERIM, G.L. (Org.) Fundamentos Pedagógicos para o Programa Segundo Tempo: 1ำ Ciclo Nacional de Capacitação dos Coordenadores de Núcleo. Porto Alegre: Ministério do Esporte, UFRGS, 2008.

PARRY, J. Resident Outdoor Environmental Education. Monterey, Estados Unidos: Healthy Learning, 2013.

PREFEITURA DE PORTO ALEGRE. Mapas e Indicadores da Vulnerabilidade Social. Porto Alegre: Prefeitura de Porto Alegre, 2007.

SOBEL, D. Wild Play. Parenting Adventures in the Great Outdoors. San Francisco, Estados Unidos: Sierra Club Books, 2011.

SOBEL, D. Place-Based Education: Connecting Classrooms and Communities. Great Barrington, Estados Unidos: The Orion Society, 2005.

THE LEAVE NO TRACE CENTER FOR OUTDOOR ETHICS (LNT). Disponível em: www.Int.org, acesso em 12 de outubro de 2013.

TILTON, B. The Leave no Trace Master Educator Handbook. LEAVE NO TRACE CENTER FOR OUTDOOR ETHICS, Boulder, CO, USA, 2003. 